\title{
Relative Chronology
}

\author{
Introduction
}

In this brief chapter I will reconsider the consequences of my findings in preceding chapters for questions of relative chronology. I will also investigate which role the vocalization of * $r$ may play in questions of Greek dialectal subgrouping.

\subsection{The Vocalization of * $r$ as a Late and Dialectally Different Development}

As we have seen in section 1.1.1, there is a fairly broad scholarly consensus that remaining instances of Proto-Greek ${ }^{*} r$ were eliminated in the mid-2nd millennium (around the 16 th c. BCE) from all Greek dialects existing at that time. In chapter 3 , this assumption received a first major blow when it was shown that word-internal * $r$ was preserved until the disintegration of Proto-West Greek. Furthermore, in chapter 2 and section 7.4 new arguments have been provided for the view of Heubeck (1972) that ${ }^{*} r$ may have been preserved in Mycenaean.

A third important conclusion is that the regular place of the anaptyctic vowel differed per dialect: the regular reflex is op in Arcadian, but $p o$ in the Aeolic dialects (cf. again chapter 3 ). This means that different processes of $a$ epenthesis took place, which affected the rhythmical structure of the syllables in question in different ways. As a consequence, the date of this epenthesis may well have differed per dialect. For instance, it is possible that the vocalization ${ }^{*} r>-r o$ - in Proto-Aeolic was a typical and old characteristic of these dialects, which took place considerably earlier than the vocalization ${ }_{0}^{*} r$ in other dialect groups such as Proto-Ionic.

Thus, the mainstream view of an early across-the-board vocalization of ${ }^{*} r$ must be rejected, but the following questions still remain:

(1) When did ${ }^{*} r$ vocalize in the Ionic-Attic dialects?

(2) When was Epic ${ }^{*} r$ eliminated?

The main instrument we can use in answering these questions is relative chronology. In this chapter I will reconsider several words and epic formulae where the outcome of ${ }^{*} r$ feeds other sound changes. Such cases might furnish a terminus ante quem for the vocalization. We will also look for evidence where 
the vocalization of ${ }^{*} r$ is itself fed by other sound changes, providing indications for a terminus post quem.

\subsection{Dating the Vocalization of ${ }^{*} r$ in Ionic-Attic}

As far as we can tell, all varieties of Ionic-Attic agree almost entirely in their reflexes of ${ }^{*} r$. Not only is - $\alpha p$ - found in the same derivationally isolated or lexi-

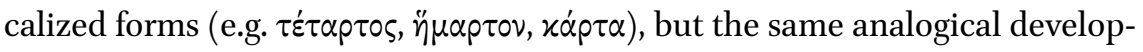

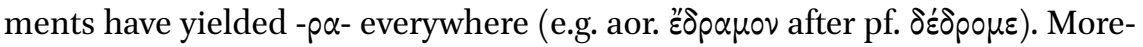
over, the analogical leveling of root vocalism in 'Caland system' derivatives has taken place in an identical way in all varieties of Ionic-Attic. Thus, $a$-vocalism

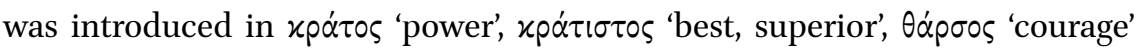

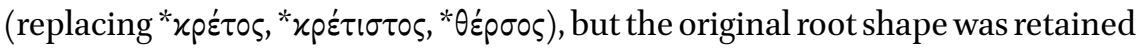
in Eastern Ion. $x p \varepsilon \dot{\sigma} \sigma \omega \nu$, Att. $x p \varepsilon i \tau \tau \omega \nu$ (with a secondary lengthening of the root vowel). It is possible to identify a few later changes, such as the productivity of the root allomorph $\theta \rho \alpha \sigma$ - in Attic (which has more innovative forms with this root than Ionic), or the loss of the lexeme $x \alpha \tau \alpha \delta \alpha p \theta \varepsilon i v$ 'to go to sleep' in Ionic (retained in Attic), but these details do not change the general picture: the vocalization of * $r$ took place when Proto-Ionic was still a unity, prior to or during the Ionic migrations to Asia Minor. This takes us back to at least the 11th or possibly 12 th c. BCE.

The generalizations and instances of leveling that occurred in spoken IonicAttic in xpatús and related forms also presuppose the lapse of some time. ${ }^{1}$ In chronological order, the most important changes are (IA = Ion.-Att. vernacular; $\mathrm{E}=$ Epic Greek):

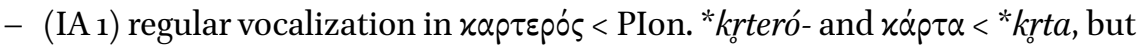

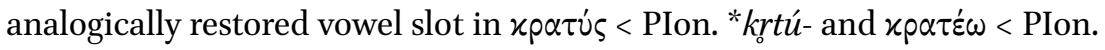
${ }^{*} k r t-\bar{e}$ -

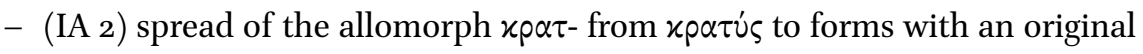

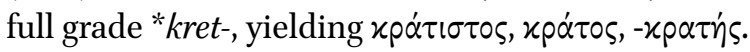

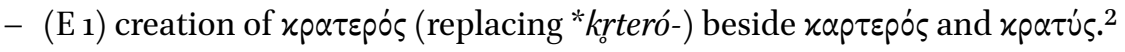

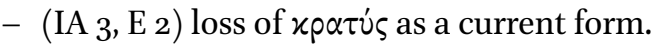

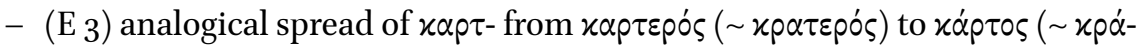

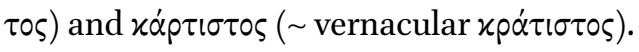

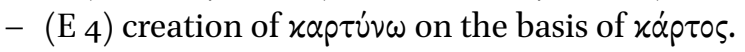

1 See chapters 4 and 5 .

2 Note that the analogy giving rise to $\gamma \lambda u x \varepsilon$ pós beside $\gamma \lambda u x u ́ \varsigma$ presupposes the phonetic reality of [ra] in $x p \alpha \tau \varepsilon \rho o ́ \varsigma$ and the simultaneous existence of $x p \alpha \tau \dot{\zeta}$. 
However, on this basis it is difficult to give a more precise estimate of the date of the vernacular vocalization. The introduction of $x p \alpha \tau$ - in various derivatives may have been carried out in several steps, and is likely to have taken some time. If we assume a late 8th c. date for the Iliad and allow some time for these analogies to take place, the data indeed seem to be compatible with an 11th or 12th century date for the vernacular vocalization.

On the other hand, there are no compelling arguments for dating the ProtoIonic change ${ }^{*} r>-\alpha p$ - further back, into the Mycenaean period. Previously, the argument for such a "high" chronology was based on the occurrence of $d$ epenthesis in Mycenaean, but in section 7.3.1 we have seen that this argument is invalid. As just mentioned, a retention of ${ }^{*} r$ in Mycenaean cannot be excluded. A new argument for a relatively early vocalization could be the idea that xuptós 'humped' directly reflects PIE * $k w_{r}$-tó- 'mutilated' (cf. section 1.3.2): this could be taken to imply that the fixation of the anaptyctic vowel before the liquid as [ər] took place prior to the elimination of labiovelars. However, it cannot be excluded that ${ }^{*}{ }^{w}{ }^{w}$ rtó- was re-vocalized as ${ }^{*} k u r t o$ - without an intermediate stage ${ }^{*} k^{w}$ artó-, at a time when * $r$ was retained in other environments.

In my view, it would be attractive to view the Ionic-Attic vocalization to - $\alpha p$ - and the unconditioned $a$-vocalization in most varieties of West Greek as part of the same development: the merger of [ə] with /a/. ${ }^{3}$ The fixation of the vowel slot and the subsequent merger of [ə] with /a/ post-dated the splitting up of Proto-West Greek: sub-dialects of the West Greek group appear to waver between - $\rho \alpha$ - and - $\alpha \rho$ - as the regular reflex, and Cretan even has a conditioned $o$-reflex after labials. This suggests that the vocalization took place as the West Greek tribes were settling the habitats where they are attested historically, i.e. in the late 12th or (more probably) 11th c. Seen from this perspective, it is attractive to view the change ${ }^{*} \partial>a$ as a late isogloss shared by Proto-Ionic and the mainland West Greek dialects. Indeed, West Greek and Proto-Ionic share other isoglosses that are plausibly dated to this period, such as the palatalization of labiovelars conditioned by following front vowels, or the 1st compensatory lengthening. The Aeolic dialects did not take part in these developments: they have ${ }^{*} r>-p o-$ and do not show labiovelar palatalization except in $\tau \varepsilon$ and $\tau \iota \varsigma$. This is remarkable in view of the probable geographic contiguity of the areas where West Greek and Aeolic dialects were spoken from

3 Note that in this statement, [ə] refers only to the epenthetic vowel emerging beside syllabic liquids that remained in existence after Proto-Greek. I am not speaking here about syllabic liquids in the environments ${ }^{*} C_{0} L H C$, ${ }^{*} C L H V$ and ${ }^{*} C L i$ discussed in section 1.2, which were subject to an earlier epenthesis, nor about the reflexes of syllabic nasals. 
the 11th c. onward. This divergence can be accounted for if the relevant developments had already taken place in Proto-Aeolic before that time, i.e. in the 12th c. or earlier. ${ }^{4}$

Thus, I arrive at the following estimates for absolute dates of the vocalization of * $r$ :

- West Greek: " ${ }^{*}$ retained at least until the early 12th c. (post quem);

- Aeolic: ${ }^{*} r$ eliminated before the second half of the 12th c. (ante quem);

- Ionic: * $r$ eliminated before the 11th c. (ante quem);

- 'Achaean': ${ }^{*} r$ perhaps retained in Mycenaean.

\subsection{Dating the Elimination of Epic ${ }^{*} r$}

As argued in chapter 8, some forms with Epic * $r$ were replaced at an early date

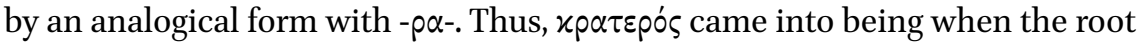

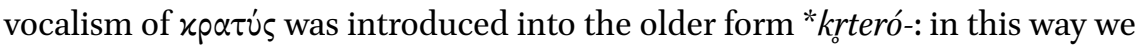

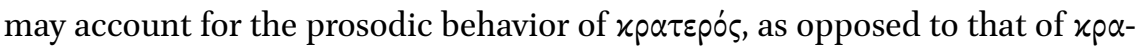
$\delta i \eta$. Other forms in which - $\rho \alpha$ - may have been introduced at an early date are

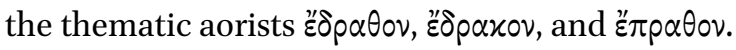

Due to such developments, Epic ${ }^{*} r$ became a relatively marginal sound. For how long was it retained? The peculiar metrical behavior of «padin, of which the onset $x p$ - is not used to make position (cf. chapter 6), suggests that the elimination of Epic ${ }^{*} r$ was fairly recent. However, it is not possible to assume that Homer still retained $r$. First of all, the split between $-\rho \alpha$ - and - $-\rho-$-, which was conditioned by the preceding consonant (chapter 7), speaks against such an

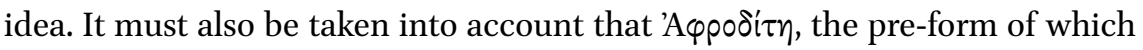
had Epic ${ }^{*} r$, is attested with $\langle p o\rangle$ already on the famous Nestor's Cup inscription from Pithecusa (dated to the last quarter of the 8th c.). Moreover, the following evidence proves that the composer(s) of the Iliad did not pronounce ${ }^{*} r$ anymore:

- In certain words whose pre-form started with consonant plus ${ }^{*} r$, the onset cluster $\mathrm{Cr}$ - is used to make length by position, even if this does not happen very often. For instance, Homer uses the onset of $\beta$ potós to generate length by position in 4 out of 41 instances (counting only those case forms of the simplex where such lengthening was an option): see section 7.2. Similarly, in

4 Cf. García Ramón (1975: 62-63), who arrives at a 12th c. date (before 1125) for PAeol. * ${ }_{\circ} r>r o$. However, I see no compelling reason for his view that all characteristic Proto-Aeolic developments necessarily took place after the Mycenaean period. 
the hapax noun phrase $\delta \rho \alpha \tau \dot{\alpha} \sigma \omega \dot{\omega} \mu \alpha \tau, \delta \rho$ - makes position; this is relevant if that phrase directly reflects an earlier *drta sōmata (cf. section 6.9.1).

- McL is applied in forms of $\beta p o \tau o ́ s$ and two other frequent words of the same metrical structure (Apóvos, Kpóvos). However, this happens mainly in case forms that were otherwise excluded from hexameter verse, such as $\beta p o \tau \omega \nu$,

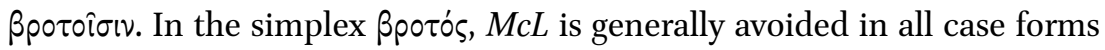
where it could be avoided, except in one instance in the Odyssey. The same distribution is found in compounds: $\ddot{\alpha} \mu \beta p \circ \tau о \varsigma, \tau \varepsilon p \psi i \mu \beta \rho о \tau о \varsigma, ~ \varphi \alpha \varepsilon \sigma i \mu \beta p o \tau о \varsigma$ have $-\mu \beta p$ - with position length, while $M c L$ scansion is found only in the

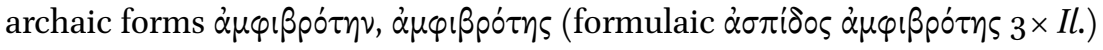
and the phrase vì $\dot{\alpha} \beta p o ́ t \eta$.

These facts show that the phonological form of 'mortal' was no longer */mrtós/ when the Iliad was composed, but already /mrotós/ or (less likely)/brotós/. It is likely that the increased acceptability of $M c L$ in forms without etymological ${ }^{*} r$ (which is manifest already in the Iliad, cf. the formulaic phrases $\mu \varepsilon \gamma \alpha \dot{\lambda} \lambda$ o1 Kpó-

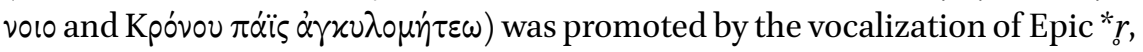
and that it was due to this vocalization that $M c L$ was established as a license in the first place. I will return to this point below.

In the Odyssey, there are additional indications suggesting that Epic * ${ }^{*}$ had already been vocalized:

- The adjective $\theta p a \sigma u s$ (cf. section 6.8.8) is preceded by the definite article $\delta$ at $O d .10 .436$, with the onset causing position length; the Iliad uses only the acc. sg. Opaбúv, but never after a metrically guaranteed short vowel, ${ }^{5}$ as well

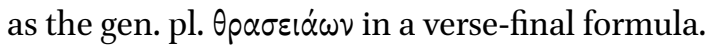

- Plural forms of Өpóvos (a word which did not have Epic * ${ }^{*}$ ) are widely used with $M c L$ scansion of the onset.

Another type of indication may come from examples where Epic ${ }^{*} r$ and ${ }^{*} u$ occur in the same context. The formal and thematic similarities between Hom.

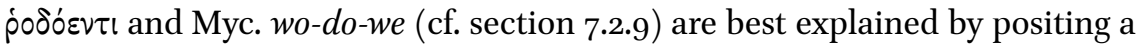
common pre-form *urdo-uent-, with Epic * ${ }^{*}$. The $o$-colored reflex po- in poóo$\varepsilon v \tau \iota$ (and in póoov) presupposes that word-initial digamma was still in place when Epic * $r$ was vocalized. Likewise, if the formula i $\pi$ ó $\delta \rho \alpha i \delta \omega v$ indeed reflects *upodr uidōn with Epic ${ }^{*} r$ (see section 9.5.2), it points in the same direction, as one would not expect *upodr idōn to develop into a form with hiatus. These observations may yield an important terminus ante quem. However, we must realize that Homer may still have pronounced digamma in words like $i \delta \omega \mathrm{v}$ ( ${ }^{*}$ uidōn) when these occurred in traditional epic material, notwithstanding the

5 In Il. 8.126, it is possible to assume the original presence of ephelcystic - $\nu$ in $\mu \varepsilon \varepsilon \varepsilon \pi \varepsilon \theta p \alpha \sigma u ́ v$. 
fact that * $u$ - was clearly absent from words that had been introduced from the Ionic vernacular (cf. the scenario in section 6.7). In this case the forms $i \pi \delta \delta \delta \rho \alpha$

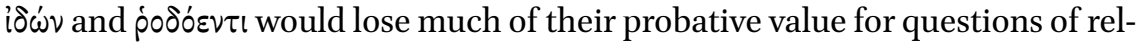
ative chronology.

However this may be, we may safely conclude that Epic * $r$ had been vocalized before the composition of the Iliad. On the other hand, it is not easy to give a more precise terminus ante quem. The metrical behavior of $x p a \delta i n$ (and

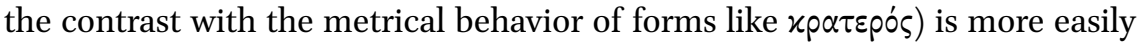
accounted for if Epic ${ }^{*} r$ was preserved relatively long. In view of this, I tentatively posit a continued presence of ${ }^{*} r$ in Epic Greek until a few generations of poets before the composition of the Iliad. ${ }^{6}$ It is conceivable in my view that the elimination of Epic * $r$ was part of the Ionicization of Epic Greek, but to argue for this would require a deeper study into the distribution of Ionic innovations in Homer, which cannot be undertaken here.

Another indication suggestive of a similar date may come from the distribution of $M c L$ scansions in Homer. How could $M c L$ become acceptable as a license, and how much time do we need for the license to acquire the (still limited) productivity it has in Homer?

Traditionally, $P L$-clusters were realized as heterosyllabic in Epic Greek, at least within a phonological phrase. When the Iliad was composed, however, $P L$-clusters at the beginning of a prosodic word in contemporary spoken Ionic were probably realized as tautosyllabic under certain conditions, judging by the fact that such scansions occur every now and then in Homeric verse, also in words without etymological ${ }^{*} r$ and in words with plosive plus $l$ (cf. section 6.5). Tow diverging tendencies are observable. On the one hand, the comparative rarity of the new type of scansion, as well as the existence of avoidance strategies, show that the Iliad poet is still uncomfortable using it: compare the distributions of the noun $\beta$ potós just discussed. On the other hand, formulae

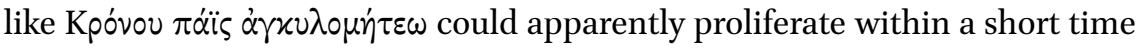
span, perhaps due to the efforts of one poet (in this case, the chief composer of the Iliad). It is desirable to have an account of how and why the license spread.

As already surmised by Wathelet (1966: 172-173), analogical transfer of the new type of scansion from one word to another may have played an important role in its spread. ${ }^{7}$ However, Wathelet's chronological scenario, in which the

6 In Van Beek 2013, I spoke of "one or two generations of poets", which is similarly vague. The point is that we are more probably dealing with a period of approximately one century, than with several centuries.

7 Wathelet also thought that tautosyllabic $P L$ was originally admissible at the medial (third foot) caesura, and that only later it became admissible also at other places, when different 
license came into being in or before the Mycenaean era (i.e. six to eight centuries before Homer) and spread only marginally to other words, is no longer tenable. In the light of the results obtained in chapter 6 , the distribution of $M c L$ scansions in Homer may make more sense also from a chronological perspective. In particular, the license may have spread further on the basis of cases where the product of the vocalization of Epic * ${ }^{*}$ could be identified with a form current in the vernacular. There are several pairs of this type in Homer:

- the middle aorist $\tau p \alpha \pi \varepsilon \dot{\sigma} \sigma \alpha \mathrm{l}$, which directly reflects the old form * trpest ${ }^{h} a i$ in Homer but has an analogically levelled vowel slot in spoken Ionic;

- the preposition and preverb $\pi \rho o ́ \varsigma, \pi \rho \circ \sigma$ - (highly frequent: है $\pi \varepsilon \alpha \pi \tau \varepsilon \rho o ́ \varepsilon v \tau \alpha$

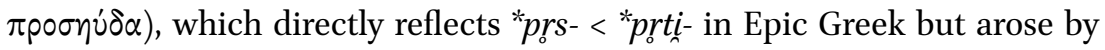
contamination with $\pi \rho o ́, \pi \rho 0$ - in Proto-Ionic (cf. section 7.2.5);

- the same scenario applies to $\pi \rho \sigma^{\sigma} \sigma \omega$ 'forward' < "prtiō;

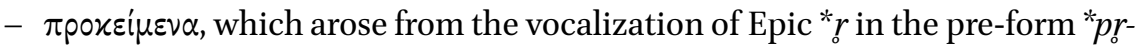
keimena, but was then identified as prefixed with $\pi$ po- < PGr. "pro-;

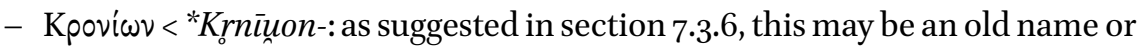
epithet of Zeus which was identified as a patronymic of Kpóvos (cf. Kpovíwv $<$ Kroniōn-) after the vocalization of Epic * ${ }^{*}$;

- $\tau \rho \alpha \dot{\pi} \varepsilon \zeta \alpha<{ }^{*}$ trpedia, which according to the assumption made in chapter 6 had been borrowed into the Ionic and Attic vernaculars.

On the basis of such cases, it is easy to imagine innovations such as the following:

- the use of $\pi \rho \circ \varepsilon \varepsilon i \mu \varepsilon v \alpha$ and $\pi \rho \delta \sigma \omega \omega$ after $\left.\right|_{T}$ enhanced the acceptability of $\pi \rho 0$ - in

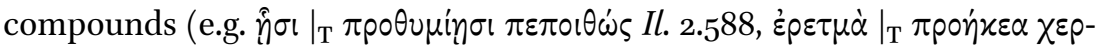

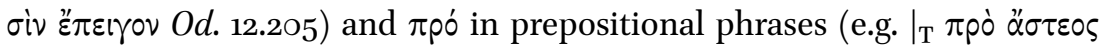

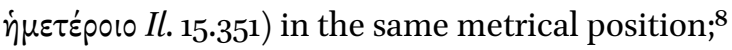

- the frequent occurrence of verse-final phrases like $\theta \hat{\eta} x \varepsilon$ Kpovíwv may have

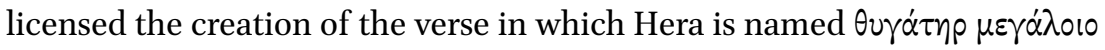
Kpóvo10 (4×Il.) (cf. section 7.3.5);

types of caesura became more prominent. Thus, as a second possible cause for the spread of $M c L$ he mentions "la multiplication des césures non médianes qui a permis aux aèdes de jouir d'une plus grande liberté de composition et de décaler à l'intérieur des hémistiches des éléments formulaires qui, situés primitivement après la coupe médiane suscitaient un abrègement autorisé par la présence de la césure elle-même." In my view, this remark is based on a misguided conception of caesura, and it is more promising to admit that the tautosyllabic scansion of $P L$-onsets gradually conquered the prosodic hierarchy. I hope to make this argument more precise in a future publication (Van Beek in prep.).

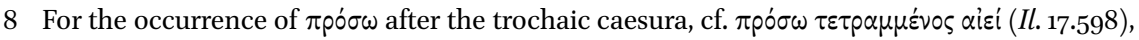
$\pi \rho \delta \sigma \omega \ddot{\alpha} \gamma \varepsilon \delta \hat{\imath} \alpha$ $\theta \varepsilon \dot{\alpha} \omega \nu$ (Il. 18.388). Cf. also the use of forms of $\pi \rho \circ \sigma \alpha \nu \delta \dot{\alpha} \omega$ in this position. 


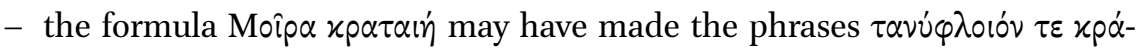

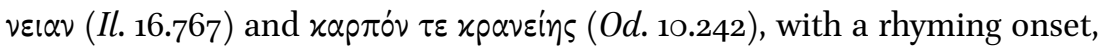
more acceptable;

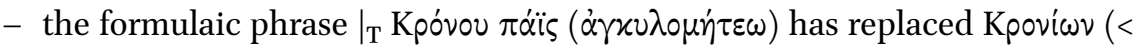
*Krniuon-) and its gen. Kpoviovos, which both occur in the same metrical position (cf. section 7.3.6).

As this brief recapitulation illustrates, it is not difficult to imagine how the new type of scansion spread relatively quickly from a small set of core instances, in which it originated from the vocalization of Epic * $r$. This is another important argument for a relatively late, but clearly pre-Homeric vocalization of Epic ${ }^{*} r$. Again, it is difficult to be more precise about the relative date with respect to the composition of the Iliad. On the other hand, it must be kept in mind that the innovative scansion was taken over by other lexemes only incidentally, and that the set of cases where it is structurally applied remains more or less stable in the Odyssey, Hesiod, and the four largest Homeric hymns. The spread of new formulaic phrases necessitating the use of $M c L$ scansion, such as Kpóvov $\pi$ áï and $\mu \varepsilon \gamma \alpha \dot{\lambda} \lambda 010 \mathrm{~K}$ óvo10, was clearly not commonplace.

\subsection{Relative Chronology: Other Sound Changes}

It is difficult to date the vocalization of word-internal ${ }^{*} r$ in the vernacular with respect to other sound changes. We have encountered the following potential clues, but unfortunately most of them do not yield very specific information:

- íóo $\rho \alpha$ cannot be used as an argument for dating the vernacular vocalization of * $r$ to before the loss of word-final stops. ${ }^{9}$ On the contrary, $\dot{\tau} \pi \delta \delta \rho \alpha$ may prove that word-final ${ }^{*}-r>-\alpha \rho$ preceded the loss of word-final stops, and that the vocalization of word-internal ${ }^{*} r$ took place later.

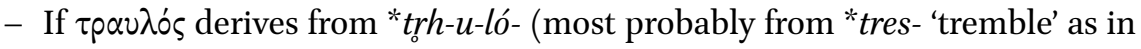

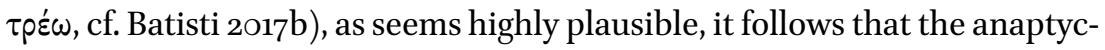
tic vowel was in place before the loss of intervocalic $* h$, which can be dated to the early Dark Ages (appr. 12th с. BCE).

- The noun $\tau p \eta \dot{p} \omega \nu$ 'pigeon' derives from an adjective *trārós 'timid' that could reflect *trh-ró-. Again, the root is the zero-grade of *tres- 'tremble', and again, the vowel slot of the vocalized form *trahró- may have been influenced by that of the base verb. This case may show that the vocalization of ${ }^{*} r$ (including the coloring of the anaptyctic vowel) took place before the loss of coda

9 Pace Meier-Brügger (1992b) and Barnes (2011); see section 9.5. 
/h/ before sonorants, which resulted in the first compensatory lengthening in most dialects. However, as argued in section 9.1.6, a pre-form *trah-arócannot be excluded. In both cases, we arrive at the 12th century as an approximate terminus ante quem for the epenthesis.

- It is not easy either to relate the vocalization of ${ }^{*} r$ to accentual developments. At first sight Wheeler's Law ${ }^{10}$ seems to have operated in the dat. pl.

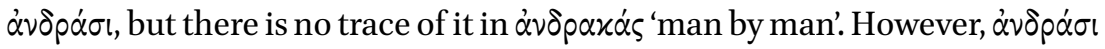
may have generalized the "pen-initial" position of the accent (directly following $\alpha v \delta \rho-)$ of the other genitive and dative forms in the paradigm, just like the stem-form $\alpha v \delta \rho$ - itself may be analogical. As for $\alpha v \delta \rho \alpha x \alpha$ s, it must be taken into account that all Greek adverbs in - $\alpha$ s are oxytone, so that the

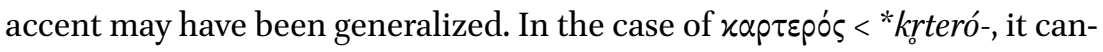
not be excluded that other adjectives in -pós influenced the accentuation.

Fortunately, two of the formulaic phrases discussed in chapters 6 and 7 contain a definite indication which allows us to date the vocalization of * $r$ in relation to another sound changes. They provide a valuable terminus post quem and are discussed in the following subsections.

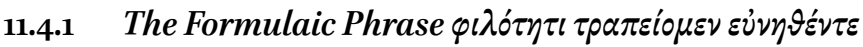

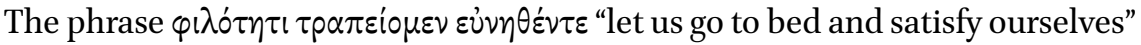
can be used as evidence once we have clarified the etymology of $\varepsilon \dot{v} v \eta^{\prime}$ 'bed; lair,

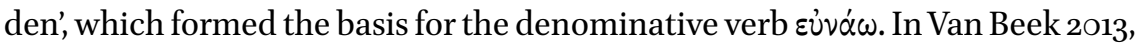
I already proposed that $\varepsilon \dot{v} v \dot{y}$ can be compared etymologically with the IndoIranian word for 'abode, safe place; womb', Ved. yóni- m. and YAv. yaona-. In a forthcoming paper, I argue for this etymology in more detail. ${ }^{11}$ In what follows I therefore assume that the Proto-Greek pre-form of घu่ví was *ieunā.

As we have seen in chapter 6, the odd root shape $\tau p \alpha \pi$ - in the 1pl. aor. subj. $\tau \rho \alpha \pi \varepsilon i$ o $\mu \varepsilon \nu$ is due to the vocalization of Epic ${ }^{*} r$ to $-\rho \alpha$-. Let me briefly review the

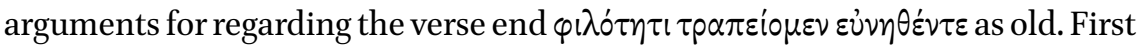
of all, everything else being equal, it would be unclear why a second hemistich starting with the outlandish form $\left.\right|_{\mathrm{T}} \tau \rho \alpha \pi \varepsilon i o \mu \varepsilon \nu$ was preferred over one starting with $\left.\right|_{\mathrm{P}} \tau \alpha \rho \pi \varepsilon i 0 \mu \varepsilon v$, with the regular aorist subjunctive. This strongly suggests that the entire phrase, including $\varphi(\lambda \circ \tau \tau \eta \tau$, existed before the elimination of Epic * $r$. This is confirmed by the syntactic analysis of the formula by Latacz (1966: 185), according to which the locative ( $\dot{\varepsilon} v) \varphi\left(\lambda \sigma^{\prime} \tau \eta \tau \iota\right.$ is a complement to

10 Retraction of an oxytone accent to the penultimate syllable in words of dactylic rhythmical structure.

11 Van Beek fthc. 
$\varepsilon \dot{\nu} \eta \eta \theta \varepsilon v \tau \varepsilon$. The presence of $(\dot{\varepsilon} \nu) \varphi \iota \lambda \cos ^{\prime} \eta \tau \iota$ in the original shape of the formulaic phrase explains why *trpēomen was artificially preserved, and why the regular form *tarpēomen was never introduced before $\varepsilon \dot{v} \eta \eta \hat{\varepsilon} v \tau \varepsilon$.

The original formula must therefore be reconstructed as " $p^{h}$ ilotāti trpēomen (i)euna $\bar{t}{ }^{h}$ ente. It now becomes clear that the formula cannot have been coined before the loss of initial yod: in a form with *ieunāthente it would not scan, neither in the dactylic hexameter nor in any of its proposed predecessors. ${ }^{12}$ In this way, I arrive at the following chronology:

1. Lenition of initial yod: *ieunā $t^{h}$ ente $>{ }^{*}(h)$ euna $\bar{t} t^{h}$ ente

2. Creation of the formula " $p^{h}$ ilotāti trpēomen ${ }^{(h)}$ eunā $t^{h}$ ente

3. Epic ${ }^{*} r>-\rho \alpha-$, raising of ${ }^{*} \bar{a}$ to ${ }^{*} \bar{e}$, quantitative metathesis ${ }^{*} \bar{e} o>\varepsilon \omega$, and

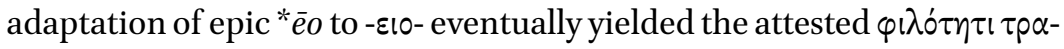

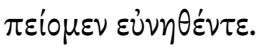

If we wish to utilize the formula as evidence for a relative chronology, we have to ascertain ourselves that the form *trpēomen (with Epic * ${ }^{*}$ ) could not be used productively in its metrical slot following $\left.\right|_{\mathrm{T}}$, for in that case " ${ }^{h}$ ilotāti trpēomen eunāthente may have been formed at any later time before Epic ${ }^{*} r$ was eliminated..$^{13}$ Fortunately, such a scenario indeed seems rather unlikely. A retention of the relic phoneme ${ }^{*} r$ in this specific form *trpéomen would have been undesirable because of the potential homonymy with the aorist of $\tau \rho \varepsilon \dot{\tau} \pi \omega$ 'to turn'. Indeed, middle forms of the thematic aorist *trp-e/o- with Epic * $r$ are reflected as $\tau p \alpha \pi \varepsilon \dot{\varepsilon} \sigma \theta_{\alpha l}$ (there are 7 instances of this stem with $M c L$ in Homer, cf. section 6.8.9). Moreover, the metrical structure of the vernacular stem form $\tau \alpha \rho \pi \eta$ - was unproblematic. This means that an incentive to preserve the stem *trp-e- (and for preferring it over regular $\tau \alpha \rho \pi \eta$-) existed, and this incentive was precisely the occurrence of *trpēomen in a formula that bridged the third foot caesura. It is therefore highly probable that the phrase " ${ }^{*}{ }^{h}$ ilotatati trpēomen eunā $t^{h}$ ente was created before (or not very long after) the vocalization of ${ }^{*} r$ in some Greek vernacular of the late second millennium.

We may now try to establish, with all due caution, a more precise date for the vocalization of ${ }^{*} r$ in Proto-Ionic. As is well-known, etymological word-initial yod is sometimes written on the Mycenaean tablets, but not always. An important word in this connection is the correlative temporal conjunction o-te 'when'

12 In theory, one could try to avoid this conclusion by assuming that the subjunctive originally had secondary endings, and that the secondary first plural (or dual) ending was still optionally *-me (cf. Ved. -ma) when the formula was coined. This assumption would, however, be completely gratuitous and without further support from attested Greek.

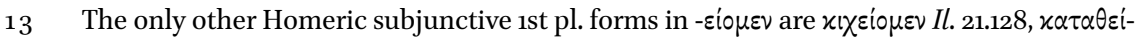

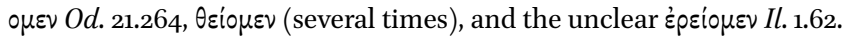


(class. ö $\tau \varepsilon$ ), which is attested four times in Linear B. Moreover, variant spellings of the same form occur, such as the forms of the relative pronoun jo- beside $o$ - (on which see Probert 2008), and in the agent noun $a_{2}-k e$-te-re $(\mathrm{KN})$ beside ja-ke-te-re (PY), perhaps representing */jakestēres/ 'menders.' ${ }^{4}$ It follows that initial yod had disappeared before our first attestations of Linear B, but not long before that. ${ }^{15}$ Similarly, that word-internal yod had already been lenited in Mycenaean is shown by the spelling of adjectives of material, where forms ending in - $\mathrm{Ce}$-jo alternate with - $\mathrm{Ce}$-o.

There are no unambiguous metrical traces of initial ${ }^{*} i$ - in Homeric Greek.

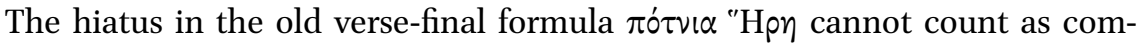

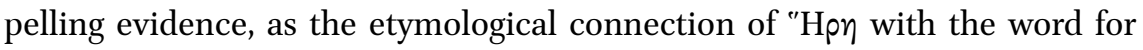
'year' (García Ramón 2016b), though not implausible perse, is not ascertained. ${ }^{16}$ This virtual absence of traces of ${ }^{*} i$ - in Homer is compatible with the idea that this sound was lenited relatively early in most Greek dialects, around the same time as in Mycenaean.

The above argument concerning the formulaic phrase $\varphi \imath \lambda \delta^{\tau} \tau \eta \iota \iota \tau \rho \alpha \pi \varepsilon i o \mu \varepsilon \nu$

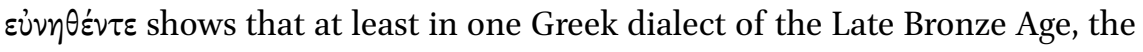
vocalization of * $r$ took place after the loss of word-initial yod. It is hazardous to go any further than this, as we do not know for certain which dialect was spoken by the singers who composed the formula. ${ }^{17}$ If we were to assume that the verse under discussion was formed by a singer whose mother tongue was Mycenaean (or a closely related dialect), it may have been formed either during the period in which the tablets were written, or else not long before that. ${ }^{18}$

14 The form a-ke-te-re (PYJn 832.1) may belong to a different lexeme in view of the absence of the sign $a_{2}$ - writing initial aspiration; it is perhaps related to the feminine forms $a$-ke-ti-ri$j a(\mathrm{KN}), a-k e-t i-r a_{2}(\mathrm{PY}), a-z e-t i-r i-j a(\mathrm{KN})$, which seem to represent /askētriai/, a derivative of $\dot{\alpha} \sigma x \dot{\varepsilon} \omega$.

15 It is less likely that initial yod was only in the process of disappearing as the tablets were written (Ruijgh 1967: 64). Willi (2009: 253) tries to push back in time the terminus post quem for the lenition of $y o d$, arguing that all we can say is that it must have occurred after the adoption of Linear B as a means to write Greek.

16 The verse-end $\pi$ ó $\tau v \alpha^{\prime \prime} \mathrm{H} \beta \eta$ (only Il. 4.2) may obviously have been created on the basis of

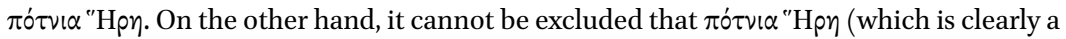

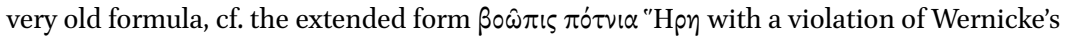
Law) is the only trace left of hiatus deriving from the loss of initial yod.

17 Note that the vocalism of the form $\tau p \alpha \pi \varepsilon i o \mu \varepsilon v$ does not help us to determine this dialect, as $-\rho \alpha$ - is simply the regular reflex of Epic ${ }^{*} r$.

18 Given the general paucity of discernable phonological differences between Mycenaean and reconstructed Proto-Ionic, we may assume a similar date for the lenition of yod in the latter subgroup. Therefore, the same chronological conclusion would be plausible if we assumed that the formula was coined by singers working in a hypothetical Old Ionic tra- 
Nevertheless, we may draw at least one significant conclusion: it is implausible that Homeric formulae with a metrical trace of ${ }^{*} r$ date back to the mid-second millennium. Whenever there is reason to assume that formulae with a trace of ${ }^{*} r$ are old, they may have been formed as late as the 13th or 12th c. BCE, or perhaps even slightly after that.

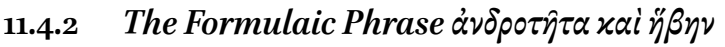

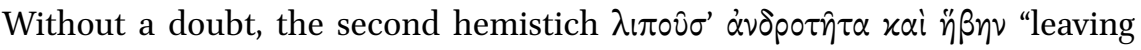
behind manly strength and the vigor of youth" is archaic: the pair of hexameters in which it occurs is used on two key moments in the story of Achilles and his wrath, the deaths of Patroclus and Hector, and it is likely to have occurred in epic poems describing the death of Achilles. ${ }^{19}$ An examination of typical death scenes in the Iliad shows that there were plenty of other ways of versifying the death of a hero, and it would be extremely unlikely that poets celebrated the most heroic deaths of all with a metrically flawed verse. Therefore, the aberrant scansion of $\alpha \nu \delta \rho 0 \tau \hat{\eta} \tau \alpha$ in its Homeric contexts is acceptable only if we assume that the phrases in which this form occurred were traditionally correct and appropriate.

In section 7.3.1, I have proposed a scenario accounting for the origin of the

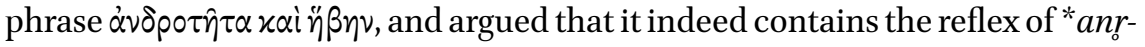
tăta. Let us now consider when the pre-form of this formulaic phrase may have come into being. The form *anrtāta must have been part of the epic tradition already before forms displaying the Proto-Ionic sound change ${ }^{*} r>-\alpha p$ - became available, that is, either before this sound change took place in the Ionic vernaculars, or before the language of epic was Ionicized. In either case, we may assume that the formula containing *anrtāta was at first retained with Epic * ${ }_{0}^{*}$. Later, when Epic * $r$ was eliminated, *anrtāta developed into *anratēta, and this form was eventually replaced by $\alpha \dot{\nu} \delta \rho \circ \tau \hat{\tau} \tau \alpha$ (by contamination with forms containing a first member $\alpha v \delta \rho \rho-)$. As we have seen in chapter 7 , it is possible that the "monumental composer" of the Iliad still sung a form with *-nr-. This would align the present case with instances of word-internal muta cum liquida scansion that arose due to the vocalization of Epic ${ }^{*} r$ following a nasal, such as

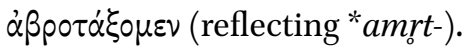

The next question to ask is: what was the shape of this formulaic phrase when it was first coined? In his earlier work, Ruijgh took great trouble argu-

dition. Concerning the Aeolic dialects and a putative Aeolic tradition, matters might be different, as the vocalization of ${ }^{*} r$ may have been a relatively early development in that group.

19 Cf. Barnes (2011: 2-5). 


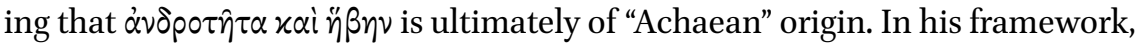
however, this would require that the Homeric formula is a transformation of a different, older Mycenaean prototype. One of his latest attempts to resolve the problems involved deserves to be quoted in full (Ruijgh 1997:43-44):

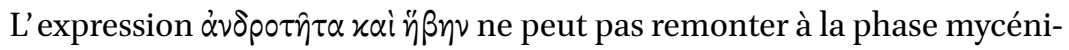

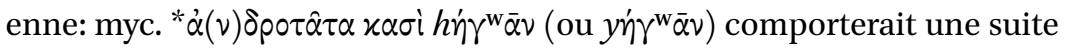
de trois brèves. En outre, la valeur mycénienne de $x \alpha \sigma i$ était probablement '(et) aussi' (Ruijgh 1967: 329-333), valeur emphatique qui ne convient pas à l' expression homérique. Autrefois, nous avons songé à la possibilité d'une expression originelle * ${ }^{*} \nu r \tau \hat{\sigma} \alpha \tau^{\prime} i \delta \dot{\varepsilon}$ y $y^{\prime} \gamma^{\mathrm{w}} \bar{\alpha} \nu$ avec la particule homérique i $\delta \varepsilon$ ' 'et'. Maintenant, nous la rejetons: en chypriote, cette particule sans doute achéenne conserve encore la valeur originelle 'et alors' (Ruijgh 1957: 55-57), qui ne convient pas elle non plus à l' expression homérique. En outre, i $\delta$ ź figure chez Homère presque toujours après la césure trochaïque. (...) En mycénien, la particule normale à valeur 'et' est -qe $\chi^{\mathrm{w}} \varepsilon$. Elle figure chez Homère dans des coordinations comme $\mu \alpha \dot{\alpha} \chi \eta$

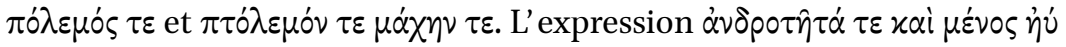
ne peut pas elle non plus remonter à la phase mycénienne à cause de la présence de $x a i$ 'et'. Dans ces conditions, nous sommes amené à postuler une formule proto-mycénienne * $\alpha^{\nu} r \tau \hat{\alpha} \tau \alpha \mu \varepsilon^{\prime} v 0 \varsigma \chi^{\mathrm{w}} \varepsilon$ 'la force de l'âge et l'élan' (...) comparer (...) $\lambda \dot{\theta} \theta \eta \psi v \chi \dot{\eta} \tau \varepsilon \mu \varepsilon \dot{v} v \varsigma \tau \varepsilon$, expression qui figure également dans le contexte de la mort d'un héros.

In other words, there are reasons to doubt that the coordinated noun phrase

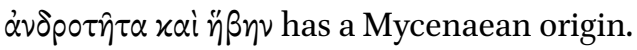

First of all, the conjunction used to connect noun phrases in the Linear $\mathrm{B}$ tablets is -qe, rather than $x \alpha$ i or a putative $\mathrm{x} k a s$. A second potential problem, not mentioned explicitly by Ruijgh, is that the expected reflex of *anrtäta would be Mycenaean ${ }^{x} a-n o-t a-t a$, for Mycenaean did not have /ro/ as the regular reflex of ${ }^{*} r$. Ruijgh's answer to this problem of chronology is to assume that the phrase containing *anrtāta was coined well before our attestations of Mycenaean, in what he calls the "proto-Mycenaean" period (i.e. the 16th or 15th с. ВСE).

This, however, leads to metrical problems: at that time, and in a shape with $x \alpha$, the formula would have been unmetrical as a second hemistich because the pre-form of $\ddot{\eta} \beta \eta$ then still had its initial yod. Indeed, this noun is generally considered to be etymologically related to Lith. jégà 'vigor, strength', Latv. jẽga 'strength; sense' and the verb Lith. jẽgti, jẽgia 'to be able, be strong'. A comparison of the forms attested in various Greek dialects and literary authors yields a 
Proto-Greek noun * $i \bar{c} \bar{g}^{w} \bar{a}$ 'vigor', ${ }^{20}$ and the Baltic forms can be derived from PIE * $(H) i e h_{1} g^{w}-e h_{2}$ or * $(H) i \check{e} g^{w}-e h_{2}$, depending on one's views on the accentuation of Balto-Slavic long vowels. ${ }^{21}$

These problems lead Ruijgh to his new reconstruction *anrtāta menos $k^{w} e$. This suggestion fails for a simple reason: if this was indeed the oldest shape of the formula, there would have been no obvious reason to replace the out-

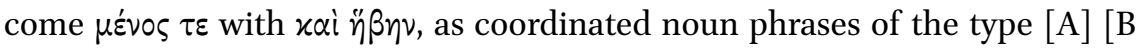
$\tau \varepsilon]$ were still current in Homeric Greek (cf. $\mu \alpha \dot{\alpha} \chi \eta \pi \dot{d} \lambda \varepsilon \mu o^{\prime} \varsigma \tau \varepsilon$, the phrase quoted by Ruijgh). Ruijgh therefore speculated that epic singers introduced the lexeme $\eta \ddot{\beta} \eta$ in order to underline the idea of a premature death. This seems highly

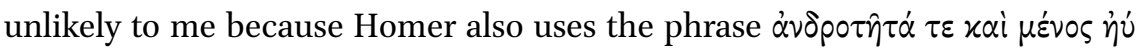

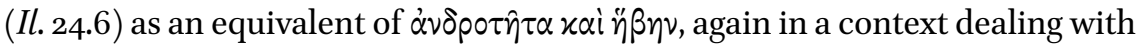
the premature death of Patroclus.

I see no sufficient reason to analyze $\alpha v \delta \rho \circ \tau \hat{\eta} \tau \alpha$ x $\alpha \dot{\imath} \ddot{\beta} \beta \nu$ as the transformation of a formula that had become unmetrical, or to assume that the formula dates from before our attestations of Mycenaean. Fortunately, as we have seen in section 7.3.1, a simple solution is available. The chronological problems cease to exist if we accept the possibility that ${ }^{*} r$ was still preserved in the late Mycenaean period and even into the second half of the 12th c. BCE, when $x \alpha$ i proliferated as a conjunction in certain dialects, including Proto-Ionic. It is in such a late Mycenaean or sub-Mycenaean context, when initial yod was no longer a prosodically relevant factor, when ${ }^{*} r$ may still have been preserved, and with

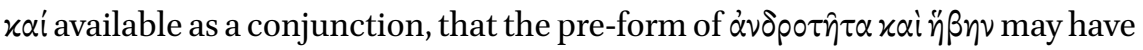
been coined. As we have seen in section 7.3.1, this is also the conclusion reached by Heubeck (1972). Within the present scenario, the form *anrtāt- underwent the regular phonological development of Epic * ${ }^{*}$ to $-\rho \alpha-$, and was subsequently contaminated with compounds in $\alpha \nu \delta \rho o-$ to yield the attested $\alpha \nu \delta \rho \circ \tau \hat{\eta} \tau \alpha$.

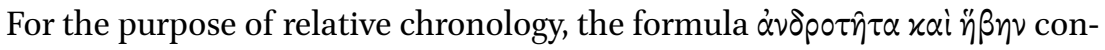
firms the conclusions reached in the preceding section: in certain prehistoric varieties of Greek, ${ }^{*} r$ remained intact until after the lenition of word-initial yod, which took place in or slightly before the 14 th с. вСЕ. ${ }^{22}$

20 Pindar has $\ddot{\eta} \beta \alpha$, and West Greek and Aeolic inscriptions have this form too (Lex Gortyn

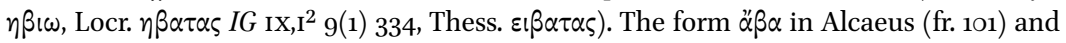
Callimachus (Id. 1.44 and 30.20 ) is probably a hyper-Aeolism.

21 It must be noted, however, that Lith. jẽgti, jégia and jègà (accent paradigm 4) have a circumflex root. This could be a case of métatonie douce in a deverbal Lithuanian $\bar{a}$-stem, on which see Derksen (1996: 141-143).

22 It seems likely to me that *anrtät- 'force' was already a poetic relic word in the second millennium. Therefore, it cannot be entirely excluded that *anrtāt-remained in more general 


\subsection{Conclusions}

I arrive at the following relative chronology for the developments that took place between Proto-Greek and Proto-Ionic:

\begin{tabular}{|c|c|c|}
\hline 1. & word-final ${ }^{*} r>{ }^{*}-a r(\mathrm{PGr})$. & Before 2. $(\dot{\tau} \pi \delta \delta \delta \rho)$ \\
\hline 2. & loss of word-final stops (PGr.) & 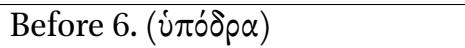 \\
\hline 3 . & ${ }^{*} k^{w}$ etur- $>{ }^{*} k^{w}$ etr- (PGr.) & Before 6. ( $\tau \varepsilon \dot{\tau} \tau \alpha \rho \tau \varsigma)$ \\
\hline 4. & $d$-epenthesis in intervocalic $-n r$ - & Pre-Linear B \\
\hline 5 . & lenition of word-initial ${ }^{*} i$ - (PIon.) & 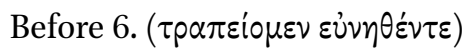 \\
\hline 6. & word-internal ${ }^{*} r>-\alpha p$ - (PIon.) & \\
\hline 7. & loss of intervocalic $-h$ - (PIon.) & 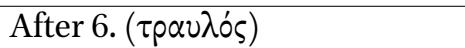 \\
\hline 8. & $\begin{array}{l}\text { loss of coda }-h \text {-before sonorant with } \\
\text { 1st CL (PIon.) }\end{array}$ & 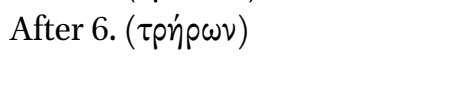 \\
\hline
\end{tabular}

Then, Epic Greek underwent the following additional changes. The term "Epic * $u$ " refers to instances of digamma that may have been preserved in traditional contexts after the sound had been lost from contemporary Ionic.
9. vocalization of Epic ${ }^{*} r>p \alpha, p o$

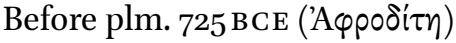
10. loss of Epic *u

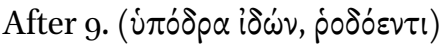
11. C-epenthesis in *anratc̄ta, * amrotos
After 9.

It is uncertain whether changes 10. and 11. took place before or after the composition of the Iliad; in my view the second option is more likely.

Note that this relative chronology relies partly on the assumption that ProtoIonic and Mycenaean underwent similar phonological developments in the later Mycenaean period, from the $15^{\text {th }}$ c. BCE onwards. Word-initial yod had been lenited not too long before attested Mycenaean; intervocalic $h$ still functioned as a normal consonant in Mycenaean and was lost only in the 12th c. BCE or soon after.

The assumed sub-Mycenaean date for the vocalization of * $r$ in Proto-Ionic and in the 'Achaean' dialects has the following advantages:

use in the epic tradition (not only in the formula under discussion) after the vernacular vocalization of ${ }^{*} r$. At least in theory, it is possible to assume the following chronology of changes: (1) * $r$ was vocalized in the vernaculars, but *anrtāta was preserved with Epic * $r$; (2) lenition of word-initial yod; (3) creation of the phrase *anrtāta kai hēbān. This somewhat diminishes the evidential value of the formula *anrtāta kai ${ }^{h} \bar{e} b \bar{a} n$ as a means to date the vocalization of * $r$ in the Greek vernaculars. 
1. It yields a more realistic time frame for the preservation of ${ }^{*} r$ in Epic Greek.

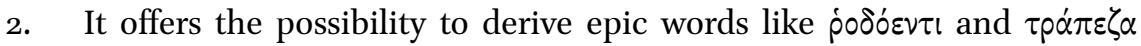
directly from a Mycenaean source form with * $r$.

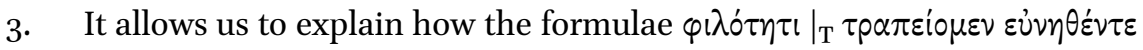
and $\left.\right|_{H} \dot{\alpha} \delta \delta \rho \circ \eta \hat{\eta} \tau \alpha \alpha \alpha \ddot{\eta} \beta \eta \nu$ came into being, assuming that they were created when ${ }^{*} r$ was still present in the (Mycenaean or Proto-Ionic) vernacular after the loss of initial yod, but before the loss of word-internal $-h$ - 